\title{
Pemanfaatan Teknologi melalui Pelatihan Penggunaan Aplikasi Google Site bagi Guru MGMP Matematika SMP Kabupaten Cirebon
}

\author{
Neneng Aminah*, Surya Amami, Ika Wahyuni, Cita Dwi Rosita, Anggita Maharani \\ Prodi Pendidikan Matematika, FKIP, Universitas Swadaya Gunung Jati, Cirebon, Indonesia \\ *Coresponding Author: nenengaminah255@gmail.com \\ Dikirim: 12-06-2021 ; Direvisi: 14-06-2021 ; Diterima: 14-06-2021
}

\begin{abstract}
Abstrak: Komputer sebagai media pembelajaran memiliki keunggulan-keunggulan dalam presentasi grafik dengan tampilan yang menarik, yang dapat dimanipulasi secara leluasa dalam bentuk representasi visual model matematika. Salah satu jenis media yang tepat dalam proses pembelajaran yaitu Aplikasi Google Site. Perangkat lunak dinamis merupakan media yang dapat memberikan kesempatan pada guru untuk meningkatkan kemampuan dalam mengajar matematika. Tujuan kegiatan PKM ini adalah memberikan pelatihan penggunaan pemanfaatan google site untuk pengajaran maupun administrasi para guru di sekolah, Metode pendekatan yang digunakan untuk mengatasi permasalahan yang dihadapi mitra adalah dengan cara mengadakan pelatihan, dan pendampingan, terkait mendesain bahan ajar berbasis literasi matematis. Target khusus dari kegiatan PKM ini adalah bertambahnya pengetahuan guru matematika SMP Kabupaten Cirebon dalam pemanfaatan google site yang selama ini dirasakan jarang ada yang menggunakan karena ketidaktahuan fungsinya. Hasil kegiatan yang telah dilaksanakan semua guru mampu mengoperasikan dan memanfaatkan google site, kegiatan menghasilkan pengetahuan bagi guru.
\end{abstract}

Kata Kunci: google site; administrasi guru

Abstract: Computers as a learning media have advantages in graphic presentations with attractive displays, which can be manipulated freely in the form of visual representations of mathematical models. One type of media that is appropriate in the learning process is the Google Site Application. Dynamic software is a medium that can provide opportunities for teachers to improve their ability to teach mathematics. The purpose of this PKM activity is to provide training on the use of google site for teaching and administration of teachers in schools. The method of approach used to overcome problems faced by partners is by conducting training, and mentoring, related to designing teaching materials based on mathematical literacy. The specific target of this PKM activity is to increase the knowledge of mathematics teachers in Cirebon Regency Junior High School in the use of google sites which so far have rarely been used because of ignorance of their functions. The results of activities that have been carried out by all teachers are able to operate and utilize the google site, the activity of producing knowledge for teachers.

Keywords: google site; administration teachers

\section{PENDAHULUAN}

Seiring dengan perkembangan ilmu pengetahuan dan teknologi (IPTEK), penggunaan teknologi menjadi salah satu pilihan untuk menyampaikan materi yang sulit menjadi lebih mudah. Salah satu jenis penggunaan teknologi dalam pembelajaran yaitu komputer, perangkat tersebut memiliki peran yang sangat penting. Komputer adalah alat pembelajaran, artinya dalam pembelajaran guru dapat memanfaatkan komputer secara optimal untuk memberikan fasilitas belajar guru. 
Penggunaan komputer dalam pembuatan bahan ajar yang perlu diperhatikan dalam mencapai kesuksesan pembelajaran ini tergantung pada model pengajaran dan kebutuhan guru.

Komputer sebagai media pembelajaran memiliki keunggulan-keunggulan dalam presentasi grafik dengan tampilan yang menarik, yang dapat dimanipulasi secara leluasa dalam bentuk representasi visual. Bloom dan Fletcher (Kusumah, 2010) mengemukakan bahwa grafik resolusi tinggi dan animasi memiliki potensi yang amat besar untuk diaplikasikan dalam pembelajaran. Beberapa kelebihan pada komputer sangat tepat digunakan dalam pembuatan bahan ajar.

Salah satu jenis media yang tepat dalam proses pembuatan bahan ajar yaitu Aplikasi Google Site. Perangkat lunak dinamis merupakan media yang dapat memberikan kesempatan pada guru untuk meningkatkan kemampuannya.

Media pembelajaran yang memberikan kesempatan pada guru untuk memanipulasi objek, dapat meningkatkan pemahaman guru. Hal ini sesuai dengan yang dikemukan oleh Piaget (Piaget \& Barbel, 2010) yang menyatakan bahwa pengetahuan dibentuk seseorang melalui interaksi dengan pengalaman terhadap objek. Hal ini sejalan dengan Romlah (2010) yang menyatakan bahwa penting mengaitkan pengalaman kehidupan nyata anak dengan ide-ide matematika dalam pembelajaran di kelas agar guru belajar dengan bermakna.

Teknologi menjadi alat penting untuk membimbing guru mengeksplorasi hubungan matematika (Aminah \& Wahyuni, 2018). Salah satu perangkat lunak dinamis yang digunakan dalam pembuatan bahan ajar adalah Google Site. Google Site merupakan salah satu Aplikasi yang difasilitasi oleh google. Penggabungan antara perintah-perintah menulis dan membaca dan menjadikan Google Site sebagai media pilihan dalam menyampaikan konsep belajar di sekolah.

Dalam pembuatan bahan ajar, terkadang merupakan kendala berat bagi guru memahami dan meningkatkan kemampuan (Prastowo, 2013). Oleh karena itu, penggunaan Google Site diharapkan dapat memotivasi guru agar lebih tertarik belajar Matematika dan lebih mudah dalam memahami konsep matematika.

Berdasarkan analisis situasi dan kajian pustaka di atas, dapat disimpulkan bahwa para guru yang tergabung dalam kelompok Musyawarah Guru Mata Pelajaran (MGMP) Matematika Kabupaten Cirebon mengalami permasalahan dalam penggunaan dan pemanfaatan media komputer sebagai salah satu alat pembelajaran. Permasalahan tersebut disebabkan oleh berbagai faktor, satu diantaranya yang sangat penting adalah pengetahuan dan kemampuan penguasaan aplikasi sehingga guru memerlukan pengetahuan tambahan.

Kegiatan PKM ini dapat dirumuskan permasalahan bagi guru anggota MGMP Matematika Kabupaten Cirebon mengenai penggunaan dan pemanfaatan komputer dan difokuskan pada pemanfaatan aplikasi Google Site. secara lebih operasional sebagai berikut. 1. Bagaimana memotivasi (membangun kemauan) diri guru untuk menggunakan dan memanfaatkan aplikasi Google Site? 2. Bagaimana meningkatkan pemahaman dan ketrampilan guru dalam pemanfaatan AplikasiMatematika dalam hal ini aplikasi Google Site? Pemahaman dan ketrampilan yang dimaksud meliputi: a) Pemahaman dan keterampilan instalasi aplikasi Google Site, b) Pemahaman dan keterampilan mengeksplorasi dan menggunakan Menu dan tool Google Site untuk mengkonstruksi materi Matematika, serta c) Mendesain aktifitas untuk pengintegrasian Google Site dalam pembuatan bahan ajar 
Berdasarkan permasalahan di atas, maka tujuan umum penulisan ini adalah untuk mengetahui penggunaan aplikasi Google Site dalam pembuatan bahan ajar di sekolah. Tujuan tersebut dapat dirinci sebagai berikut: Peserta pelatihan diharapkan mampu: 1. Termotivasi untuk menggunakan dan memanfaatkan aplikasi Google Site dalam pembuatan bahan ajar, 2. Melakukan instalasi aplikasi Google Site, 3. Mengeksplorasi dan menggunakan Menu dan tool Google Siteuntuk mengkonstruksi objek Matematika, serta 4. Mendesain aktifitas untuk pengintegrasian Google Site dalam pembuatan bahan ajar.

Pelatihan penggunaan dan pemanfaatan aplikasi Google Site bagi Guru dalam program pengabdian masyarakat ini diharapkan dapat memberikan pemahaman dan juga kemampuan guru dalam penggunaan dan pemanfaatan aplikasi Google Site yang akan berdampak pada peningkatan hasil belajar guru MGMP Matematika SMP Rayon Sumber Kabupaten Cirebon. Adapun manfaat kegiatan secara rinci ádalah sebagai berikut, (1) Bagi Guru yaitu menjadi termotivasi untuk menggunakan dan memanfaatkan aplikasi Google Site dalam pembuatan bahan ajar, (2) Bagi Sekolah yaitu kemampuan guru menggunakan dan memanfaatkan aplikasi Google Site dalam pembuatan bahan ajar bermanfaat bagi sekolah dalam meningkatkan mutu pendidikan peningkatan rata-rata mata pelajaran Matematika.

Sasaran kegiatan ini adalah guru MGMP Matematika SMP Rayon Sumber Kabupaten Cirebon yang mempunyai kemauan dan kemampuan untuk dilatih penggunaan aplikasi Google Site. Pemilihan dan penetapan sasaran pelatihan ini mempunyai pertimbangan rasional-strategis dalam kaitannya dengan upaya peningkatan hasil belajar Matematika guru dalam proses pembuatan bahan ajar tentang penggunaan dan pemanfaatan salah satu aplikasi Matematika, yaitu Aplikasi Google Site.

Kegiatan pelatihan ini merupakan bentuk pembinaan kemampuan guru untuk menggunakan dan memanfaatkan aplikasi Google Site dalam pembuatan bahan ajar. harapan dari pelatihan ini guru memiliki potensi, pengetahuan dan kemampuan untuk menggunakan dan memanfaatkan aplikasi Google Site dalam pembuatan bahan ajar. harapannya di sekolah agar menggunakan dan memanfaatkan aplikasi Google Site dalam pembuatan bahan ajar untuk dapat terus meningkatkan prestasi belajar.

\section{METODE}

Metode pendekatan yang digunakan untuk mengatasi permasalahan yang dihadapi mitra adalah dengan metode penjelasan, pelatihan, dan pendampingan mendesain bahan ajar berbasis literasi matematis. Secara rinci kegiatan Program Kemitraan Masyarakat (PKM) dijelaskan seperti pada Diagram 1. 
Diskusi antara Tim PKM dengan mitra untuk memperoleh gambaran permasalahan yang dihadapi mitra, kebutuhan mitra, serta penentuan masalah prioritas yang akan ditangani dalam kegiatan PKM yang akan dilaksanakan

Koordinasi antara Tim PKM, mitra, dan narasumber untuk menentukan waktu pelaksanaan kegiatan, materi pelatihan, dan jadwal kegiatan.

Melakukan persiapan pelaksanaan kegiatan (pembelian alat dan bahan, penyiapan lokasi)

Pelaksanaan Kegiatan :

1. Penjelasan terkait mendesain bahan ajar dan kemampuan literasi matematis

2. Pelaksanaan pembuatan desain bahan ajar

3. Pendampingan dalam menyusun bahan ajar.

Partisipasi Mitra dalam Pelaksanaan Kegiatan :

1. Guru mengikuti jadwal kegiatan yang telah di buat

2. Guru membuat desain bahan ajar berbasis literasi matematis

3. Guru mengimplentasikan bahan ajar yang telah dibuat

$\underline{\text { Evaluasi }}$

1. Membandingkan kompetensi mitra sebelum dan sesudah adanya pelatihan.

2. Membandingkan tingkat pengetahuan, kemampuan dan ketrampilan mitra dalam mendesain bahan ajar

Diagram 1. Metode Pelaksanaan PKM

\section{IMPLEMENTASI KEGIATAN DAN PEMBAHASAN}

\section{Kegiatan Pelatihan}

Kegiatan pelatihan ini di ikuti oleh seluruh peserta yang tergabung dalam kelompok Musyawarah Guru Mata Pelajaran (MGMP) Matematika Kabupaten Cirebon. Adapun materi yang disampaikan pada kegiatan pelatihan ini yaitu:

(1) Penegenalan software Google site, (2) Manfaat Google Site, (3) Penggunaan google site, (4) Praktek penggunaan google site

Dari materi yang telah disampaikan semua peserta mendapatkan transfer ilmu bahwa Google Site banyak sekali penggunaannya. Guru mengetahui fungsi (1) Memberikan tugas latihan/ ulangan online melalui laman website, (2) Mengumpulkan pendapat orang lain melalui laman website, (3) Mengumpulkan berbagai data guru/ guru melalui halaman website, (4) Membuat Site ulir pendaftaran online untuk sekolah, dan (5) Membagikan kuesioner kepada orang-orang secara online. Pada materi yang disampaikan juga guru akhirnya banyak mengetahui kemampuan berteknologi. Berikut adalah gambar kegiatan pelatihan. 


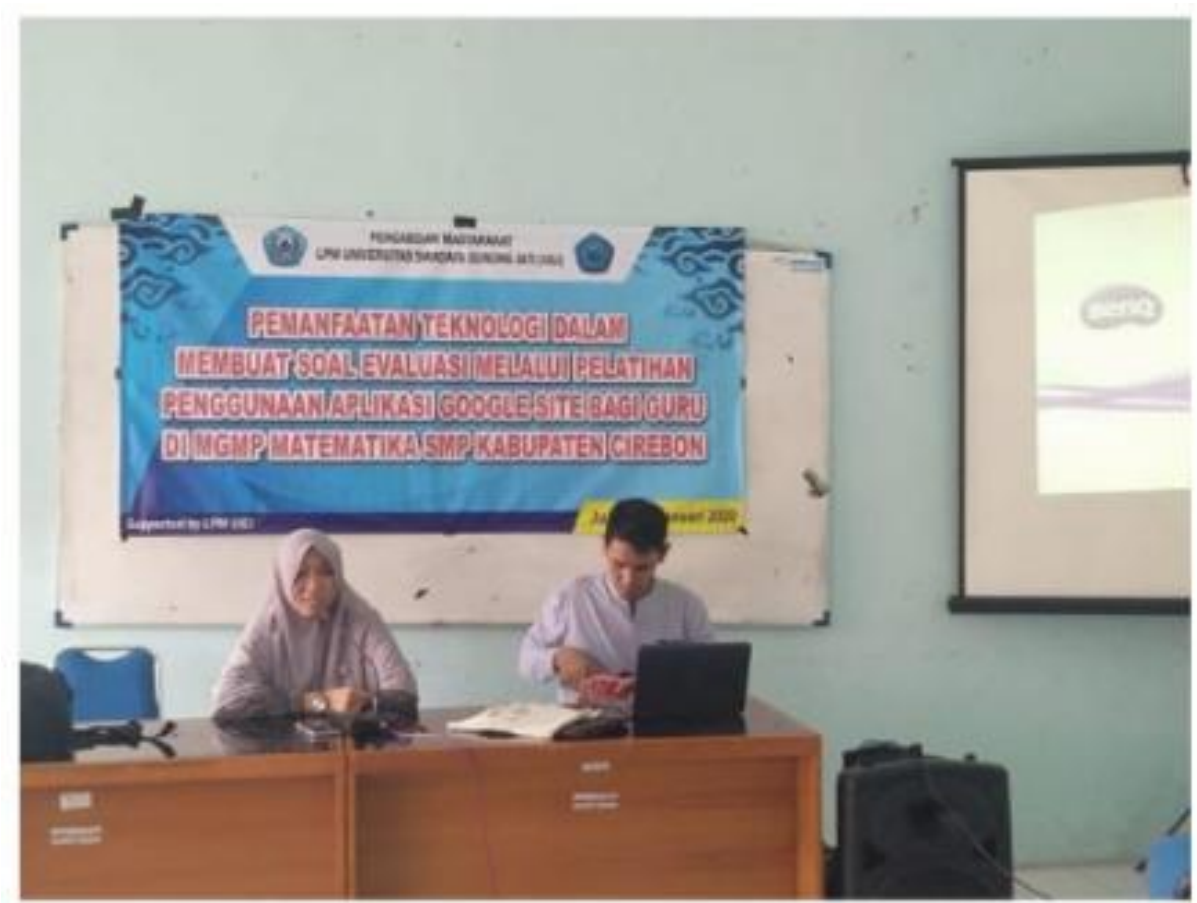

Gambar 1. Kegaiatan Pelatihan

\section{Kegiatan Keterampilan}

Seluruh peserta dengan seksama mengikiti jalannya pelatihan, selain materi, para peserta juga diberikan pelatihan keterampilan bagaimana cara membuat desain pada google site. Berikut hasil keterampilan yang dibuat oleh guru selama kegiatan pelatihan berlangsung.

Setelah melaksanakan keterampilan membuat tabel google site, kemudian guru diberikan latihan bahan materi untuk ditampilkan pada google site, terlihat guru bersemangat untuk mendiskusikan materi bahan ajar yang akan dibuat. dari seluruh peserta dibagi menjadi empat kelompok. Berikut gambar kegiatan guru saat membuat desain materi yang akan di upload pada google site.

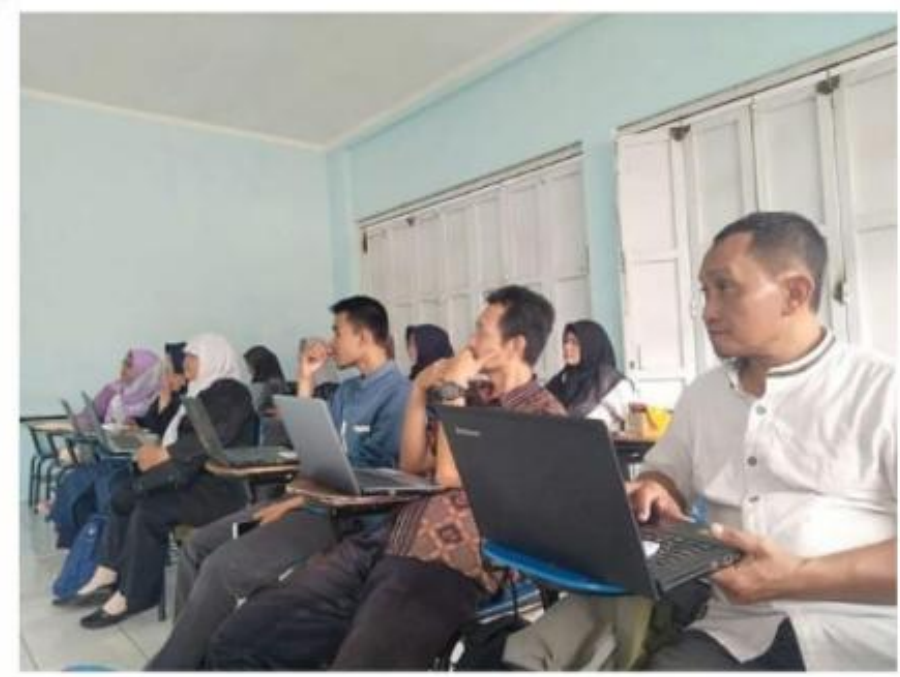

Gambar 2. Suasana diskusi guru menyimak pemaparan materi Pemanfaatan dan penggunaan aplikasi google site 


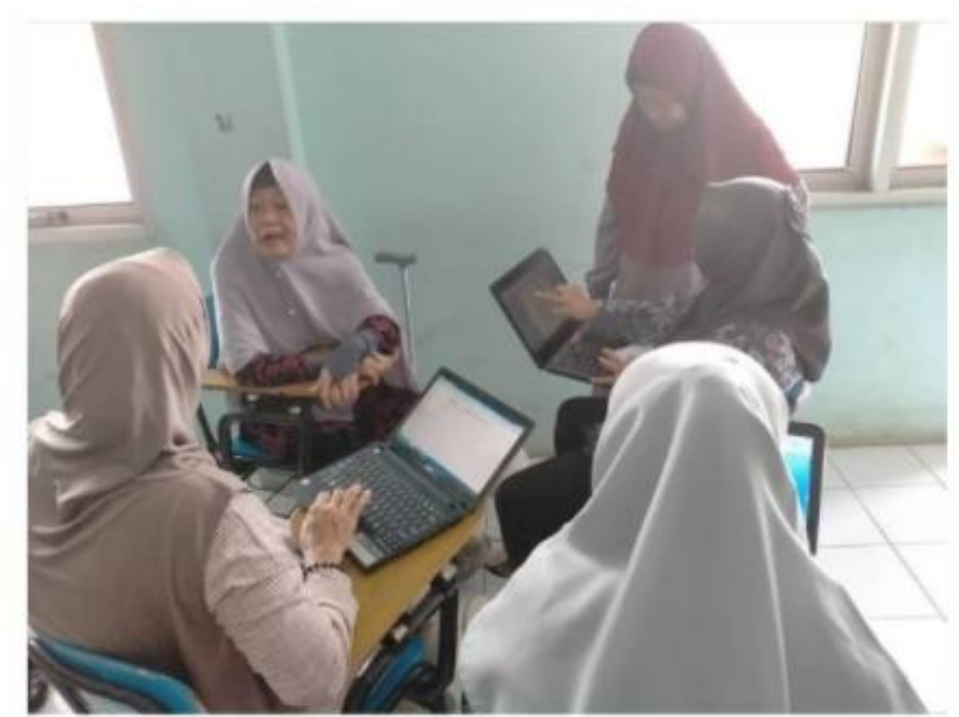

Gambar 3. prakek embuat bahan ajar yang ditampilkan pada aplikasi google site

Indikator keberhasilan selama proses pelatihan dengan melihat:

a. Kemampuan dan keterampilan Guru-guru dalam pemanfaatan dan penggunaan AplikasiGoogle Site yaitu

1) melakukan instalasi Google Site

2) mengeksplorasi dan menggunakan menu dan tool Google Site untuk

3) mendesain aktifitas untuk pengintegrasian Google Site dalam pembuatan bahan ajar.

b. Jumlah Guru-guru yang mampu dengan baik dan secara terampil melakukan kegiatan teknis penggunaan Aplikasi Google Site dalam proses pembuatan bahan ajar di sekolah.

Indikator keberhasilan pelatihan ini adalah sebagai berikut:

Tabel 1. Indikator Keberhasilan Kegiatan PKM

\begin{tabular}{lcl}
\hline No & Persentase & \multicolumn{1}{c}{ Indikator keberhasilan } \\
\hline 1. & $>80 \%$ & $\begin{array}{l}\text { peserta Guru-guru memahami kegiatan } \\
\text { pelaksanaan pelatihan penggunaan dan } \\
\text { pemanfaatan AplikasiGoogle Site dalam } \\
\text { pembuatan bahan ajar }\end{array}$ \\
\hline 2. & $>75 \%$ & $\begin{array}{l}\text { peserta/Guru-guru mampu mempratekkan yaitu } \\
\text { penggunaan aplikasi google Site }\end{array}$ \\
\hline 3. & $>50 \%$ & $\begin{array}{l}\text { peserta/Guru-guru bersedia mensosialisasikan } \\
\text { kemampuan penggunaan aplikasi Google Site }\end{array}$ \\
\hline
\end{tabular}

\section{KESIMPULAN}

Berdasarkan kegiatan pengabdian kepada masyarakat yang telah dilakukan dapat disimpulkan bahwa mitra yakni seluruh peserta yang tergabung dalam kelompok Musyawarah Guru Mata Pelajaran Matematika Kabupaten Cirebon dikatakan berhasil, dan mereka merasa antusias karena selain mendapatkan pengetahuan secara materi selama praktek guru pun mendapat bimbingan, sehingga mereka mendapatkan pengetahuan baru. 


\section{UCAPAN TERIMA KASIH}

Terimakasih disampaikan kepada Lembaga Pengabdian Masyarakat (LPM) Universitas Gunung Jati dan Fakultas Keguruan dan ILmu Pendidikan (FKIP) yang telah memberikan dukungan baik moril maupun materiil pada kegiatan ini, serta kepada masyarakat khususnya guru yang tergabung dalam kelompok Musyawarah Guru Mata Pelajaran Matematika Kabupaten Cirebon.

\section{DAFTAR PUSTAKA}

Aminah, N. and Wahyuni, I. 2018. Design of Capability Measurement Instruments Pedagogic Content Knowledge (PCK) for Prospective Mathematics Teachers. J.Phys.:Conf.Ser.1013 012112. online : http://iopscience.iop.org/issue/1742$\underline{6596 / 1013 / 1}$

Piaget, J and Barbel, I. 2010. Psikologi Anak, Terjemahan: Miftahul Jannah, Yogyakarta: PT. Gramedia

Prastowo, A. 2013. Panduan Kreatif membuat Bahan Ajar Inovatif, Menciptakan Metode Pembelajaran yang Menarik dan Menyenangkan. Yogyakarta: Diva Press

Romlah, 2010. Psikologi Perkembangan. Malang: Universitas Muhammadiyah Malang Press. 